\title{
To merge or not to merge: The institutional re-design of telecoms regulation in the Netherlands
}

\section{Kutsal Yesilkagit}

\section{Introduction}

On 1 January 2013, the Independent Postal and Telecommunications Authority (OPTA) will be merged with the Dutch Competition Authority (NMa) and the Consumer Authority (CA). This will bring an end to an almost two decades long debate in the Netherlands on the position of OPTA and on the regulation of the telecommunications sector. From all the available alternatives that have recurred within the numerous debates, the Dutch government has finally chosen for the merger between the telecommunications regulator and the general competition regulation. With their decision, the Dutch policymakers signal that they have come to perceive telecommunications as a sector that has become sufficiently competitive and therefore no longer in need of ex ante regulation by a sector-specific regulator. The decision is backed by the argument that the gap between ex ante and ex post regulation has substantially faded during the past. This decision goes directly against the critical views of a number of authoritative actors, among whom economic analysts of the Central Planning Agency and academic telecommunications experts. Among the counterarguments we find that the view that the telecommunications market is still dominated by the incumbent; that the convergence of telecommunications and media sectors are rapidly converging due to innovations in transmission infrastructures and software; and, finally, that the regulation of content is a matter of public interest that cannot be safeguarded by competition regulation alone. Hence, the debate is surrounded by a substantial amount of ambiguity and complexity.

The central aim of this chapter is to examine the decision of the Dutch government to merge the telecommunications regulator with the general competition regulator. More specifically, in this chapter we examine why the Dutch government chose for merging OPTA with the NMa given the existence of structural alternatives for this merger? The relevance of this question lies in the consequences of institutional design choices more generally. The bigger issue that lies behind this question is that of the logic of institutional design of regulatory agencies. The institutional design of regulatory agencies strongly correlates with the capacity of policymakers to affect the behavior of agencies. As a consequence, institutional design will also affect the outcome of regulatory policies and decisions. The institutional design of regulatory agencies, to put it differently, affects both the transaction costs for the exercise of political control and the costs regulatory outputs impose on the regulatees of the agencies - i.e. firms, individuals or groups (Moe 1995; Huber \& Shipan 2002). More specifically, the institutional design of a regulatory regime - the set of regulatory authorities and procedures in place within a specific sector - imposes upon governments coordination costs i.e. costs of coordinating the regulatory regime - and upon market parties the costs of regulatory incoherencies - i.e. the degree of transparency and ambiguity of regulatory decision-making within a given regulatory regime (Verhoest et al 2010).

The central puzzle in this chapter thus is linked to the general question of institutional design in the public sector. This is an issue that has received wide attention in the political science and public administration literature and is mainly centered on the question why public organizations are designed as they are (Moe 1995; Horn 1995; Epstein \& O'Halloran 1999; Gilardi 2002; Lewis 2003; Yesilkagit \& Christensen 2010). The explanatory variables within this literature are mainly based on political mechanisms, such as the degree of policy conflict between policymakers, the (future) uncertainty concerning political turnover, and the fear of politicians to lose control over the bureaucracy. In general, the political science literature on institutional design claims that design choices reflect political considerations of political parties and policymakers. In contrast to the main focus and resulting arguments in this literature the organizational sciences offer alternative 
explanations for outcomes of institutional design (Donaldson 2001; Aldrich 2008). Within the organizational sciences, contingency-based explanations, which stress the effects of the attributes of the task-environment of organizations, form the central theses of various models of institutional design. In contrast to the previously mentioned political explanations, organizational explanations claim that the design of organizations is a function of the degree of adaptation of organizations' design to the task-specific attributes of the environment in which organizations exist. In this chapter we will compare our empirical findings concerning the merger case with the theoretical claims of both literatures. The substantial impact that the institutional design of regulatory agencies has for governmental coordination costs and regulatory incoherence for market parties requires that we better understand the mechanisms of institutional design.

The structure of this chapter is as follows. Section Two presents various models of institutional design that specifically address the context of telecommunications. The section focuses on the alternative models of regulatory design within telecommunications regulation against the background of technological convergence, competitiveness and the protection of public interests.

As such, this section will present the main debate among academics and practitioner who focus on governance issues within the telecommunications sector. Section Three will show that each model generates different costs of coordination and coherence upon policymakers and market parties. It will further show that different models represent significantly different alternative cost-benefit ratios from among which policymakers have to choose. In Section Four, I present the political and organizational sciences perspectives on institutional design. The framework provides the background that allows us to better understand the ratio behind the decision of the Dutch government. This section develops two opposite arguments: (1) if political considerations prevail in the decision-making process the choice of regulatory models that minimize coordination costs become more likely; (2) if contingency consideration prevail, then regulatory models that incorporate the attributes of the technological environment of telecoms regulation become more likely. Both claims are assessed in Sections Five and Six. In Section Five, the background of the liberalization of telecommunications in the Netherlands is described, followed by a detailed description of the political debates on regulatory design within the Dutch telecommunications sector between 1997 and 2011, the period preceding the Dutch government's decision. Section Six focuses in on the decision, i.e. on the views of the relevant actors and the motivations of policymakers as stated in official documents, and compares these insights with the theoretical claims made in Section Four. The chapter ends with a conclusion.

\section{Variety of regulatory models in telecoms regulation}

Technological innovations are rapidly transforming the landscape within the telecommunications sector. Not only are technological capabilities changing but also the legal and administrative contexts of telecoms as developed and developing economies become densely interconnected through communications networks that span the entire globe and connect various regions. Another key development within this sector is caused by convergence, i.e. the fading of traditional boundaries between media, communication, and content as the consequence of technological changes. These developments - increasing competitiveness and convergence - pose a challenge for the design of institutional models of telecommunications regulation. This section presents the variety of alternative designs for telecoms regulation that exist and are debated within the telecoms sector. Garcia-Murillo and Maclnnes (2003) distinguish between five alternative models for the telecoms sector: single-sector regulation, multi-sector regulation, formal cooperation model of regulation, ICT convergence regulation, and general competition regulation. We will briefly discuss each of these alternatives.

\section{Single sector regulation}

Garcia-Murillo and MacInnes (2003) present the single sector-specific telecoms regulator as the basic reference point for alternative institutional designs of telecoms regulation. In most countries, the authors argue, where various sectors (media, broadcasting) and utilities (post, energy, water, 
railways, telecommunications) emerged separately at different historical stages, the telecommunications sector used to be regulated by a single specialised telecoms regulator. The telecoms sector consisted, technically speaking, of telephone and telegraph lines, as well as radio frequencies. Historically, again, single sector regulation was also the typical feature of regulatory regimes in other utilities sectors and infrastructure networks. However, given the dynamics of technological developments within the telecoms sector since the 1980s, regulatory designs for telecommunications came under the pressure of growing competitiveness and convergence. This dynamics distinguishes regulatory approaches within telecoms from those within the railways and postal sectors. Due to differences in technology, regulatory design in these sectors was often single sector-specific regulatory agencies where multi-sector regulation was less prevalent (Jordana \& Levi-Faur 2010).

\section{Multi-sector regulation}

Multi-sector regulation as an alternative mode of regulatory design comes into vogue when technologies across utility sectors converge and legal frameworks across sectors start coinciding and overlapping with each other. There exist several specific arguments that support multi-sector regulation over single-sector regulation: improved monitoring of large corporations with activities in multiple industries; the reduction of the risks of capture by industry and politics; uniformity of regulatory rules and principles for multiple sectors; improved regulatory arbitrage by agency; resolution of conflicts; and the possibilities for creating economies of scale and scope (Schwarz \& Satola 2000; Herring \& Carnassi 2008). Given the commonalities between different utility sectors, multi-sector regulation may lead to efficient use of lawyers, economists and accountants. However, each sector develops at different rates: innovations within telecommunications occur at a higher pace than developments within water provision, for example. There are limits to multi-sector regulation, however. When the various utilities addressed by the regulator diverge too much from each other, then the economies of scale would be lost. Another problem could be that multi-sector regulators lack the required in-depth expertise of specific technical aspects of the different utilities they regulate (Henten, Samarajiva \& Melody 2003).

\section{Formal regulatory coordination}

A third alternative model is 'formal regulatory coordination'. In contrast to the previous alternative model, single-sector utility regulators need not to merge into a single body, but need to agree upon a formal mechanism of cooperation and coordination between their organizations. Hence, for formal regulatory coordination to work properly, it is necessary that a formal coordination procedure and/or body is established where representatives from various (utility) regulatory authorities are represented. In this body, these representatives would convene regularly and exchange views and experiences with each other. This 'inter-agency board' (Garcia-Murillo \& Maclnnes 2003) would serve as a platform for representatives from market parties, societal actors, other ministries as well as agencies. The advantage of this arrangement, the authors argue, is that it prevents regulatory arbitrage and venue shopping by the regulatees, since all regulators regularly keep each other informed about their decisions, such that venue shopping by industry actors loses informational advantages. A possible drawback of this alternative is the issue of representation: who will decide who is on the board and whose interests will be represented.

\section{ICT regulator}

A fourth alternative regulatory design for telecoms regulation is an ICT regulator. An ICT regulator is responsible for the regulation of information and communication industries. This type of organisational solution would only be feasible in markets where "great competition exists, leading to the rapid introduction of new services and changes in the structure of the industry. Under these circumstances, the perception on the part of regulators is that great changes are happening in the market and that changes in regulation may also be necessary" (Garcia-Murillo \& Maclnnes, 2003: 64). ICT regulators would encompass, hence, the media, telecommunications, and computer sectors. There should be a clear and determined view among policymakers that content and technologies are irrevocably merging due to the technological advancements (Samarajiva, Mahan 
\& Barendse 2002). And this fact gives rise to similar problems as they exist with multi-sector regulators. Whereas cost-effectiveness can be gained by sharing generic expertise, the sectors maintain a range of sector specific elements that need specialist attention. An issue, the authors state, is which regulator will absorb the activities of the other (Garcia-Murillo \& MacInnes, 2003: $65)$.

\section{General competition regulation}

The final mode of regulatory design mentioned by Garcia-Murillo and Maclnnes is the general competition authority. One reason for a government to delegate telecoms regulation to the general competition authority would be the conviction that sector-specific regulation of the telecoms market has become obsolete due to the maturation of competition within the sector. Internet may play an important role in such an assessment, as the World Wide Web has freed up institutional and infrastructural hindrances for market entrance in many areas of small and medium-sized trade. Another reason may be ideological: policymakers with a strong pro-market inclination have principal objections towards any form of government intervention in markets. A main advantage of the market option is that regulatory coordination costs are reduced immensely as the need for administrative coordinating arrangements vanishes. The downside of this option is that social and other non-economic goals will not be pursued. Another possible downside is that the sector will fall under the general competition authority that has no qualified ICT specialists when overseeing this sector.

\section{Governmental coordination costs and regulatory incoherencies for market parties}

The previous section sketched the 'design menu' for telecoms regulation. Each of the design alternatives however imposes variable costs upon regulators and regulatees. In this sense, we can argue that each alternative is suboptimal. Either the chosen design increases the costs of coordination of the regulatory regime, or it does put burdens upon market parties who must comply to the regime. Verhoest et al (2010) categorize these costs as coordination costs - i.e. the costs imposed upon governments for steering the regulatory regime - and costs emanating from regulatory incoherence - i.e. the costs imposed on market parties as a consequence of the degree of (lack of) transparency and coherence in regulatory decision-making. This section describes how these costs are related to or generated by the models presented above.

The costs of coordinating the regulatory regime are the costs carried by policymakers. More precisely, the costs of regulatory coordination are a function of the number of regulatory bodies that operate within the same regulatory domain or in domains that overlap with each other. How much costs policymakers are willing to take may depend, among other things, on the level of control they prefer to exert upon their regulators or on the complexity of the problem they must address. In general, one can think of two opposite situations. At one end of the scale, policymakers could opt for bearing all the costs emerging out of the need for coordination upon government itself. For example, if we take an individual ministry as a reference point, the costs of coordination will increase with the number of (single sector) regulators for which the ministry is responsible: the more regulators that fall under the responsibility of a single ministry, the more coordination efforts that ministry has to make for coordinating the actions of these regulators. The costs of coordination also increase when several regulators fall under the responsibility of two or more ministries. In this case, coordination costs include the costs of coordinating regulatory policymaking between involved ministries as well as the costs of coordinating regulatory policy implementation. At the other end of the scale, coordination costs decrease when the scope of regulation increases. This is the case where a single multi-sector regulator is responsible for multiple regulatory domains or when ex ante and ex post regulation is delegated to a single regulator authority. This type of design yields lower costs of regulatory coordination for the government, as only one single ministry becomes the principal of one single 'omnibus' regulator. The costs of coordinating different sectors or the cost of balancing ex ante and competition regulation is in this situation 'delegated' to the regulatory authority. The balancing of ex ante and ex post regulation or the balancing and matching of sector specific regulation of multiple sectors is shifted upon the regulatory authority. 
Coordination then becomes a matter of internal organizational design, which involves among other things the design of divisions for the different regulatory tasks and the pooling of expertise (technical, legal, economic) within separate units or divisions.

Market parties also face costs from regulation. Their costs arise from the same source as that of the government - i.e. number of regulators - but the effects are of a different nature. The costs market parties namely face is related to the level of regulatory coherence. Regulatory coherence is the extent to which regulatees are faced, or perceive themselves to be faced, with a transparent and coherent set of regulations (Verhoest et al 2010). For market parties, costs increase when regulatory incoherencies increase. Regulatory incoherencies arise when several regulatory actors within the sector or across sectors do not coordinate well and take decisions that are not consistent with each other. This, too, can be illustrated by considering two extreme positions. At one end of the scale, regulatory coherence will be high when the number of regulatory actors is low or when market parties only have to deal with a single regulatory actor. In terms of the models discussed above, costs will be low in situations where a single sector regulator monitors market parties whose main activities (perfectly) fit with the sector that belongs to the jurisdiction of the regulatory actor. It also corresponds to a situation in which an 'omnibus' regulator (i.e. multi-sector, ICT or general competition regulation) regulates the activities of multi-industry market parties. At the other end of the scale we find situations where the costs of regulatory incoherencies are high for market parties. Such a situation may exist when two or more single sector regulators have overlapping or complementary competences for the same sector. In this situation, market parties, whether they are single-industry or multi-industry firms, become dependent on the adequate coordination of regulation between multiple regulatory authorities. In Table 1, for each of the models described above one finds in somewhat more detail the costs associated with coordination and coherence.

Table 1 Costs of regulatory coordination and regulatory coherency for policymakers and market parties

\begin{tabular}{|c|c|c|}
\hline & Government: Coordination costs & Market parties: Incoherency costs \\
\hline Single sector-specific regulator & $\begin{array}{l}\text { High, when multiple single sector } \\
\text { regulators under one ministry } \\
\text { (implementation coordination costs) } \\
\text { Higher than above, when regulators } \\
\text { are spread over multiple ministries } \\
\text { (policymaking and implementation } \\
\text { coordination costs) }\end{array}$ & $\begin{array}{l}\text { Low, when single industry firms fall } \\
\text { within scope of single-sector } \\
\text { regulator. } \\
\text { High, when multiple single sector } \\
\text { regulators regulate single multi- } \\
\text { industry firm }\end{array}$ \\
\hline Formal regulatory coordination & $\begin{array}{l}\text { Should lead to a decrease in the } \\
\text { level of coordination costs for the } \\
\text { government if multiple regulatory } \\
\text { actors are capable of coordinating } \\
\text { adequately and virtually act as a } \\
\text { single body in specific cases. } \\
\text { However, this increases coordination } \\
\text { costs with the regulatory actors }\end{array}$ & $\begin{array}{l}\text { Should lead to more coherence if } \\
\text { regulatory actors manage the } \\
\text { coordination mechanism well, vice } \\
\text { versa. Costs rise if relevant } \\
\text { regulatory actors are not } \\
\text { represented within coordination } \\
\text { mechanism. }\end{array}$ \\
\hline Multi-sector regulator & $\begin{array}{l}\text { Medium, as coordination costs are } \\
\text { decentralised to the internal } \\
\text { organisation of the agency, but } \\
\text { responsibility for various utility } \\
\text { sectors may be spread across } \\
\text { different ministries. }\end{array}$ & $\begin{array}{l}\text { Market parties, both single- as well } \\
\text { as multi-industry firms, could gain as } \\
\text { this creates a one-stop shop for their } \\
\text { sector. }\end{array}$ \\
\hline ICT convergence regulator & $\begin{array}{l}\text { Low, as coordination costs are } \\
\text { decentralised to the regulator. The } \\
\text { costs of internal coordination will be } \\
\text { lower than in case of a multi-sector } \\
\text { regulator, as the sector is converged }\end{array}$ & $\begin{array}{l}\text { Low for market parties that offer } \\
\text { broad media and communication } \\
\text { services in converged sectors. } \\
\text { Incoherency increases when market } \\
\text { parties comprise non-ICT business } \\
\text { activities as well }\end{array}$ \\
\hline
\end{tabular}




\begin{tabular}{|l|l|l|}
\hline Competition regulation & $\begin{array}{l}\text { Very low as government delegates } \\
\text { authority to a single agency. Internal } \\
\text { coordination costs may arise for } \\
\text { matching ex ante and ex post } \\
\text { regulation. }\end{array}$ & $\begin{array}{l}\text { cow for market parties operating in } \\
\text { comay arise for market parties if their } \\
\text { activities are spread across sectors } \\
\text { that develop unevenly towards } \\
\text { competitive state. }\end{array}$ \\
\hline
\end{tabular}

It should be clear, however, that policymakers play a key role in the level of both types of costs, because it is policymakers that choose the type of regulatory actor. The empirical questions that lie in front of us are twofold: First, how will policymakers weight the coordination costs with respect to incoherency? In other words, is the institutional design of telecoms regulation primarily driven by the coordination costs faced by the government or are the incoherencies for market parties (and often related administrative burdens for the sector) a leading driver of regulatory design? Second, regardless of the weighting of these two parameters there is the question of how much coordination costs policymakers are willing to take and, similarly, how much incoherencies they would allow to occur in the implementation of regulation?

\section{Theoretical Framework}

The questions in the concluding paragraph of the previous section are ultimately questions of institutional design. Given the variable (expected) costs and benefits attached to each design alternative, which alternative will policymaker choose? In this section I discuss two alternative theoretical frameworks for institutional design that I then will use as a framework to examine the decision of the Dutch government to merge the telecoms regulator with general competition regulator. The first framework is that of contingency theories. Contingency may be expected to (partially) explain the decision of the Dutch government as this perspective takes the environment of regulation into account. Since convergence is a strong force in the environment of telecoms regulation we may expect that the presence (or absence) of convergence may have had an effect on the decision of the Dutch government. To this framework is juxtaposed a political science institutional choice framework. This framework is deemed potentially relevant as the case under study in this chapter concerns the (re-) allocation of costs over political and economic actors as well as governance issues pertaining to the level of political control that policymakers may exert over regulatory agencies. On the basis of this political perspective we should expect political considerations of bureaucratic control prevail during the institutional design process.

Contingency theories claim that organizational design is a function of the attributes of the environment or context within which an organization operates (Donaldson 2001; Aldrich 2008). Contingency theories see changes and differences in organizational structure between and within organizations as a result of changes and differences within and between the environments of organizations. Simply put, there must be match between the structure of an organization and the organization's task-environment. A central idea here is hence that there is no one best way of organizing. One of the main premises of contingency theory is that organizations are open systems that freely interact with their environment. The type of technology that is prevalent at any given time within the environment of the agency is the basic frame of reference for organizational fit. As there is no best way to organize, organizational design must fit with the characteristics of the environment. This in turn implies that different types of environment demand different types of organization. The organizational ecology variant of contingency theories argues that environmental mechanisms 'select' some organizational forms over other (Hannan \& Freeman 1989; Amburgey \& Rao 1996). This selection occurs as a consequence of environmental pressures, by a 'fit' between the characteristics of the organization and its environment. Organizations may obtain their goals from the environment. Whereas theories of bureaucracy presuppose that goals are known and are unambiguous, contingency theory claims that organizational goals are exogenous and are partly determined by elements in the environment of an organization. Second, organizations do not have fixed boundaries and may vary depending on the prevailing circumstances in the environment of the organization. Finally, there needs to be a match between the technologies the organization applies internally to produce its main outputs or manage its main activities with the external 
resources and environmental demands for certain technological qualifications on products or activities (Aldrich 2008)

The theory of structural choice emphasizes that organizational forms are the resultant of political choices (Moe 1995; Lewis 2003). More precisely, the design of an organization - and thereby decisions to create, merge, split or terminate the organization - are taken by policy makers driven by their preferences for control over the organization's operations, on the one hand, and the uncertainty of policymakers about the time they have to exert this control. The right or authority to (re-)design organizations is not a fixed property of one group of policymakers and is transferred to other groups of policymakers whenever political turnovers, due to elections or other mechanisms of political turnover, take place. This implies that in democratic political systems the right to design organizations can be transferred from one group of policymakers to another group of policymakers after each instance of political turnover. Although the design of organizations is a transferable right from one set of policymakers to another, the actual exercise of this right or the effectuation of it depends on the institutional rules that shape the process of organizational design. In political systems where the consent of the majority is required to take decisions of organizational design and where formal rules to acquire such majorities are complex, it is more costly to (re-)design organizations than in political systems where a minority or single political actor can unilaterally make decisions (Tsebelis 2002; Hammond 1996) In more general terms, the theory of structural choice claims that the design of organizations is a function of political decision-making, where the rules of the political decision-making process determine the level of (legislative) costs that policymakers in power have to make for (re-)desiging organizations.

These two theoretical frameworks suggest that policymakers can be influenced by substantially different factors when choosing between institutional designs. When these frameworks are applied to our case it is possible to develop the following two lines of reasoning. First, should the logic behind contingency theories prevail in the motivations of policymakers we would expect that the regulatory model that is chosen have a relatively high degree of fit with its environment. If we apply this logic to the decision of the Dutch government to merge the telecoms regulator with the general competition authority we should find the following: policymakers chose for a merger between OPTA and NMa because (a) the telecoms market has become a competitive market that can be addressed by competition regulation and/or that (b) technological convergence between telecommunications and media has not developed such that an ICT regulator would fit within its task-environment. Second, political explanations of institutional choice do not attach much weight to the task-environment of organization but more on the political management of the regulatory regime and give more weight to the electoral considerations of their decisions. Reasoning from a political perspective, then, the merger between OPTA and NMa could be the resultant of policymakers' preference for the minimization of the political costs of coordinating the regulatory regime and the lowering of administrative costs for market parties emanating from regulatory incoherencies.

\section{Telecoms liberalization and regulation in the Netherlands}

\subsection{From state monopoly to liberalisation (1915-1996)}

In the Netherlands, telecommunications networks and services have been a public monopoly for almost the entire $20^{\text {th }}$ century. Until 1915 , telecommunications (i.e. fixed telephones and telegraphy) has been primarily organized and owned by the private sector and operated only within the larger municipal areas. In 1915, the state hived-in the telecoms sector into the public sector by creating the Post Telephone and Telegraph (PTT) as part of several ministries (e.g. first Interior and later Public Works). From 1945 onwards, several governmental commissions investigated and discussed possible models for a more autonomous PTT. Subsequent governments, however, resisted these plans, as they feared a loss of control and income from the revenues of the PTT. During the 1970s the debates turned in favour of more autonomy for the PTT. Financial problems, 
i.e. huge deficits in the operations of the PTT, made the Government decide to raise the charges for telecommunications services. This met with huge resistance in the following years. This act was perceived as 'sneaky taxation' and viewed as the Government using the PTT as its money-spinner. By the end of the 1970s, PTT management (proponents of autonomy) and politicians (opponents) were pitted against each other.

The advent of a neo-liberal government in 1981 finally set in motion the process of the privatisation of the PTT. Subsequent cabinets established several committees to investigate policy options for reform of the telecommunications sector. Long before the Terminal Directive of the European Economic Communities (88/301/EEC) and, as if in anticipation of the 1984 Green Paper on the role of telecommunications in the construction of Europe, the centre-right cabinet of Christian Democrats and Conservative Liberals ordered these committees to think about the consequences of the burgeoning information technologies on the institutional design of the telecommunications sector. This primarily involved the structure and position of the PTT. In 1986, the plan to corporatise the PTT was endorsed by a majority of the Parliament; the incorporation of the PTT officially took hold in 1989. The Dutch State remained the sole shareholder for a period of five years and sold the majority shares in 1994; PTT became KPN.

Between 1990 and 1998, the Dutch Government gradually opened up and liberalised the telecommunications sector in the Netherlands (Levi-Faur 1999). Following the corporatisation of KPN and the liberalisation of terminal equipment and value added services, subsequent governments liberalised data communications services by allowing for circuit and packet switched data transport services and the resale of leased line capacity. The mobile phone market took a start in 1995 with the licensing of KPN and Libertel, a new entrant owned by the ING Group (banking and insurance) and the UK mobile phone provider Vodafone. Two new 'interim' acts enacted in 1996 allowed for competition for, among other things, the use of cable infrastructure and other alternative fixed infrastructure (e.g. railway cables) for telecommunications services other than voice telephony. This was followed in 1997 with the liberalisation of voice telephony as well. In 1998, parliament enacted the Telecommunications Act. In 2004, this act is altered and reenacted. The major change has been that the 2004 Act is less sector-specific than the initial 1998 Act. Due to rapid technological changes the 2004 act is technology-neutral and given the development of competition in the telecommunications sector, the new act is more based on the general competition act.

\subsection{The regulatory regime after liberalization (1997-2011)}

Between 1997 and 2011, despite the recurring debates on the reorganization of the OPTA, the regulatory regime within the telecommunications sector has remained relatively stable. The arrangement consisted of, including OPTA, of six main regulatory actors. Next to OPTA these were the Ministry of Economic Affairs, the Competition Authority (NMa), the Radiocommunications Agency (Agentschap Telecoms), the Media Authority (Commissariaat for the Media), and the Consumers' Authority (Consumentenautoriteit). These regulatory actors have cooperated on several regulatory issues, including competition regulation, ex ante sector regulation, consumer protection, and media and electronic communications convergence regulation. Cooperation was organized on the basis of so-called "cooperation protocols" (samenwerkingsprotocollen) which had to be signed between these regulators on the basis of the law.

\section{OPTA}

The Independent Authority for Post and Telecommunications (Onafhankelijke Post- en Telecommunicatie Autoriteit) was established by law, on 5 July 1997. The boar of the OPTA consists of appointed members that have to be independent experts from different disciplines (economics, law, telecommunications, etc.). These members are appointed, suspended and fired by the Minister of Economic Affairs. The OPTA is competent for the post and telecommunications sectors. The OPTA is an Independent Administrative Body (IAB) under the framework 
responsibility of the Ministry of Transport, Public Works, and Water Management. The mission of the OPTA is stated in Article 1.3 of the 2004 Telecommunications Act. The main mission of OPTA is to accomplish the goals that are stated subsections 3 and 4 of Article 8 of the Framework Directive 2002/21/EC. The OPTA must hence see to the development of the European Union internal market and protect the rights of consumers within the EU. Article 1.3 subsections 2 and 3 prescribes that the OPTA should always take notice of the decisions of the European Commission and that whenever OPTA does not follow these decisions, that it should provide an informed reason to both the Commission and the Minister of Economic Affairs.

\section{The Ministry of Economic Affairs}

The Ministry of Economic Affairs is responsible for policy preparation in the domain of market regulation. The most important part of the Ministry's policy preparation work is the transposition of EU directives. It also is the parent department of OPTA. The Ministry of Economic Affairs became OPTA's parent department only in 2004, however. Before Economic Affairs, it was the Ministry of Traffic and Public Works that was the primary responsible ministry for telecommunications regulation, as the PTT was initially a directorate general of this ministry before it became privatized. The Minister of Economic Affairs has several tasks within the context of telecommunications regulation. First, it is responsible for the building and provision of antennas for wireless communication networks. Second, the ministry allocates frequencies for mobile phones, radio and television broadcasts, communication networks in the area of defense, shipping and air traffic, and in the field of RFID applications. The Radiocommunications Agency is the executive agency that implements the frequency policy under the direct authority of the Minister. Finally, the agency is responsible for the regulation of numbers and domain names. The Ministry of Economic Affairs draws the Number Plan, specifying which numbers are to be allocated for which purposes and functions, whereas the OPTA is responsible for the actual allocation and assignment of numbers.

\section{The Dutch Competition Authority}

The Dutch Competition Authority (NMa) is an Independent Administrative Body established by the Dutch 1997 Competition Law. It is headed by a board and has about 350 staff members (2009). The Dutch Competition Authority is charged with the implementation of European and national competition laws. The NMa consists of three units: competition, legal affairs, and energy and transport. The economic staff bureau is the seat of the Chief Economic Advisor. The NMa is a general regulator and its competencies stretches over all economic sectors. The NMa has farreaching powers: it conducts market analyses, investigates and monitors market behaviour, and has a host of sanctioning powers.

As regards telecoms regulation, the NMa has been delegated the authority to monitor vertically integrated public corporations with significant market power as designated by Art 82 EC (see Art. 6.a.20 Telecommunications Act). The relationship with the OPTA is further based on a cooperation protocol that is signed on 5 January 1999 and revised and renewed on 24 June 2004. The cooperation protocol is mandatory for the OPTA and the NMa. Article 18.3 (1) of the Telecommunications Act and Article 150 of the Postal Act obliges the OPTA to sign such an agreement with the NMa. The cooperation protocol obliges OPTA and NMa to coordinate with each other when they exercise their powers, to agree on common interpretations of similar norms within the general competition law and the telecommunications laws and to consult each other when they investigate cases that relates and inform each other about relevant information as regards the misuse of a dominant market position or information regarding concentration with respect to electronic communications networks and services. In individual cases in the past the collaboration between the NMa and the OPTA has been good. The view that the OPTA is a temporary body that should ultimately become part of the NMa has dominated political discussions since the creation of the OPTA in 1997. 


\section{The Media Authority}

The Dutch Media Authority (DMA) is set up as an Independent Administrative Body by the 1988 Media Law. The DMA is an Independent Administrative Body and has a legal personality. The DMA is governed by a board that consists of a chairperson and two to four members, who are all appointed by the Minister of Education, Culture and Sciences for a period of five years. DMA is placed between the government and the broadcasting companies. In The Netherlands, there exist two kinds of broadcasting companies: the public broadcasting companies and the private broadcasting companies. The public broadcasting companies are in essence private associations, i.e. third sector bodies that are almost fully subsidized by the government. The older public broadcasting companies are founded within the context of the Dutch pillarized society. Broadcasting companies originally represent the various religious and social groups in the Dutch society. To be sure: given the convergence of radio, internet and television frequencies the media here includes the world wide web, newspapers, television, and radio. The tasks of the DMA are: licensing of public and private broadcasting companies; monitoring the financial solidity of the public broadcasting companies and checking their (commercial) side activities; controlling the implementation of the rules concerning sponsoring and advertisements by public and private companies; adjudicating between operators, program producers and users; advisory functions as regards media policy; monitoring of concentrations in the media market and advising the general competition authority NMa; and act as a sector-specific consumers authority.

\section{The Radiocommunications Agency}

OPTA has no competences for frequency allocation. This is delegated to an arm's length agency under the direct control of the Ministry of Economic Affairs. The Radiocommunications Agency was created in 1927 under the name of the Radio Control Agency of the PTT. The agency has existed since then under different names and under different ministries. The Radiocommunications Agency in its current form is a semi-autonomous 'agentschap' under the Ministry of Economic Affairs and was established in 2007. The agency is responsible for obtaining and allocating frequency space and monitoring its use. This all takes place under the direct authority of the Minister of Economic Affairs. The Radiocommunications Agency is fully subjected to ministerial control. Under its authority falls wired as well as wireless electronic communication networks. The Radiocommunications Agency regulates and implements various telecommunications acts and decrees.

\section{Consumer Authority}

Finally, the Consumer Authority (CA) was created in 2007 and is an agency of the Ministry of Economic Affairs, Agriculture and Innovation. It was established as a result of repeated instances of compliance problems in various consumer markets. The role and growth of television programs dedicated to consumer issues and televised complaints of individuals played a role in the establishment of the authority. Another formal reason for the establishment of the CA was the enactment of Regulation 2006/2004 on consumer protection cooperation. Although it has been granted direct oversight and enforcement powers, the CA has no formal independence. The Ministry is still politically responsible. It prepares the authority's annual report and sends it to the Second Chamber. Also, the Minister may issue policy guidelines as well as directly intervene in specific decisions in individual cases. Finally, the CA is headed by a director who is appointed by the Minister of Economic Affairs, Agriculture and Innovation. The power of the CA stems from both private as well as administrative law. Under private law, the CA is entitled to file cases with a private law court whenever the CA wishes to acquire a cease and desist order in cases where there is a breach of collective consumer interests (hence, not in cases of individual consumer interests). The CA can also ask private law courts to declare binding the settlements between two parties. A final instrument of the CA is that it may support different sectors to initiate self-regulation schemes. 


\section{A prelude: The OPTA debate until the merger decision}

The regulatory design of telecoms regulation has been the centrepiece of a highly volatile debate. The discussion already started during the process leading to the establishment of OPTA. There were fierce debates between the Minister of Economic Affairs and the Minister of Transport, Public Works. The main bone of content was the issue under which ministry's responsibility OPTA should reside. Another issue concerned the independence and competences of OPTA. Finally, there were questions about whether there would be need for a sector-specific telecoms regulator at all. Some demanded that competences regarding telecoms regulation should be delegated directly to the $\mathrm{NMa}$. One of the main reasons behind the government's hesitation to create an independent telecoms regulator was the objection of the governing coalition against the creation of Independent Administrative Bodies (IABs), a type of body for which ministers had a limited scope of formal accountability (cf. Yesilkagit 2004). The decision to establish OPTA as an IAB after all was because of the recognition that (1) the liberalised telecommunications and the yet to be liberalised postal markets required an independent 'arbiter' and that (2) the EU directives required the creation of independent regulators (Kamerstukken II 1996-1997, 25128, nr. 3).

The establishment of an independent OPTA under the responsibility of the Ministry of Transport, Public Works and Water Management instead of Economic Affairs caused nevertheless a series of turf wars between the two ministries. An important source for these turf wars was the amendment of the 1998 Telecommunications Act submitted by the Second Chamber in April 1998 that inserted a provision that stated that the OPTA had to reach consensus with the NMa in cases concerning competition rules within the telecoms sector. This amendment summoned the OPTA and NMa as well as their respective ministries to set up coordination mechanisms both at the departmental (policymaking) and agency (implementation) levels. The NMa considered the amendment a breach of its competences and independence. This discussion rose again in 2001. The Ministry of Economic Affairs submitted to the Second Chamber a bill that would transform the NMa into an Independent Administrative Body. ${ }^{1}$ This proposal also put the position of the OPTA in relation to the NMa on the agenda. Quite surprisingly, the Ministry of Transport and Public Works itself, the parent department of OPTA, proposed to integrate OPTA as a division ("chamber") within the NMa. The telecoms and postal sectors as well as two prominent members of the Council for Transport and Public Works supported the proposal.

The OPTA reacted furiously against this proposal by claiming that it went against European regulations. The Netherlands would be the only Member State with a telecoms regulator integrated within the general competition authority; hence a regulatory system without an independent telecoms regulator. The independence of OPTA was saved after all by a positive evaluation of the Telecommunications Act and the role played therein by OPTA by the consultants of Twijnstra \& Gudde. This report was among the reasons why the cabinet finally decided to maintain an independent telecoms authority, at least for another four years. Nonetheless did the cabinet add to this that after the next evaluation of the Telecommunications Act the OPTA would become a chamber of the NMa after all. The chairman of OPTA's board reacted that he could not understand why the Dutch Government would want to deviate from models of regulatory design that prevail in the other Member States. He added that telecoms market was far from being competitive and that this would remain so for the foreseeable future. And, he continued, should there be any preference for a different regulatory model, then it should be the 'British model', where Ofcom is designed as an ICT regulator encompassing the entire spectrum of electronic communications services and networks: broadcasting, internet and telecommunications.

\footnotetext{
${ }^{1}$ Since its establishment in 1997, the Dutch Competition Authority had been a Directorate General of the Ministry of Economic Affairs, albeit one that enjoyed a large amount of de facto autonomy from the Minister.
} 
After this, the merger debate went subterfuge for another five to six years only to resurface again during a parliamentary hearing in August 2003 on the framework concerning the new

Telecommunications Act. The centre-right parties demanded more stringent rules for transparency with regard to the grounds upon which the OPTA regulates. They also suggested to decrease the degree of independence of OPTA and to bring it closer under the range of the Ministry. The centreleft Labour Party argued instead that provisions within the current administrative law are sufficient for maintaining a check on the powers of OPTA. This was in line with the preferences of competitors to the incumbent KPN, who were in favour of more independence for the OPTA and wanted the influence of the Ministry to be reduced, so that the relationships between the European Commission and the OPTA would not be hampered by too many interventions by the Ministry.

Two years later, in October 2005, the independence of OPTA again became an issue of debate. During a parliamentary debate with the Minister of Economic Affairs, members of parliament from the Labour Party, in contradiction to their position two years earlier were sceptical towards the independence of the OPTA. The criticism zoomed in on the authority of the OPTA to issue policy guidelines independently and without prior consent from the minister. MPs, especially from the centre-right Christian Democrats, pleaded in favour of a clear demarcation between policy and administration, meaning that OPTA being an executive agency should not be given policymaking authorities. The Conservative Liberals had revised their view too as they now expressed to trust the capability of the OPTA to act independently from the Minister. They were now only concerned with the rising costs of regulation for market parties. Like in previous times, the transformation of the OPTA into a chamber of the NMa was raised again but not long afterwards dropped from the agenda for reasons that cannot be traced. The debates in October 2005 had only one tangible outcome: OPTA was finally transferred from the Ministry of Transport and Public Works to the Ministry of Economic Affairs.

Two years later a new and previously disregarded alternative was brought to the table. Next to the existing alternative of the merger between OPTA and NMa, a merger between OPTA, the Radiocommunications Agency and the Media Authority emerged as a viable alternative to the OPTA-NMa merger. The Conservative Liberals were the most fervent supporters of the OPTANMa merger, followed by the Christian Democrats and centre-left parties. There was a general belief now that the telecoms market had become highly competitive. A merger between NMa and OPTA would also sit well with the complaints of the Second Chamber that the regulatory landscape had become too fragmented. Finally, this merger was also looked upon as an attractive downsizing measure. The OPTA, however, held a different view as regards merger candidates. OPTA set aside its principled objections against merging with any other regulator and turned in favour of a merger between OPTA, the Media Authority and the Radio-communications Agency. For the OPTA started to acknowledge the changing technological environment of telecommunications and the need for an ICT regulator to address the growing convergence between telecoms, media and content.

The final act in this debate so far is the formal decision of the Dutch government to merge OPTA and NMa. By the letter of 28 March 2011, the Minister of Economy, Agriculture and Innovation informed the Dutch Parliament about his intentions to merge three non-financial market regulators before the start of the year 2013. From 1 January 2013, the Dutch Competition Authority (NMa), the Independent Postal and Telecommunications Authority (OPTA), and the Consumer Authority will be merged into a single new regulatory authority. The name of the new regulatory authority is dubbed Consumers and Market Authority and will be based on three pillars: consumer protection, sector-specific regulation and general competition regulation. The new body will obtain a collegial board consisting of three persons and have an independent status.

\section{Analysis}

One thing should become clear from the previous description of the 'OPTA debate': the running thread throughout these years was the position of OPTA vis-à-vis NMa and the constant pressures 
from politicians to integrate telecoms regulation within the general competition authority. The creation of an ICT regulator only recently appeared in the debate. In this section we will focus on the decision of the government to merge OPTA and NMa and analyze this decision from the theoretical perspectives presented in Section Four. The first question we will address is this: Since the cabinet did not opt for a merger between the Media Authority and OPTA, does this then imply that there has not been a sufficient degree of convergence between the media and electronic communications domains such that the creation of an ICT convergence regulator was not feasible? When answering this question we will discuss a report of the authoritative Central Planning Bureau and a report of the RAND Corporation. The second question turns the attention towards possible political explanations: Does the decision of the government to merge NMa and OPTA imply that lowering the costs that emanate from regulatory coordination and incoherence have been the main determinant of the decisions? Before we start answering these questions, we will first establish the fact whether at the time of the merger debates, according to expert views, there was a convergence between the communications and media sectors.

\section{Convergence or no convergence?}

The first source that we consult to answer this question is a recent report of the Central Planning Bureau, the independent economic advisory agency of the Dutch government. According to the report of the CPB analyst De Bijl (2011), there exists a high degree of convergence between various media and electronic communications sectors. The report argues that technological advances within the domains of Internet, media, telephony and network infrastructure (i.e. the emergence of glass fiber) enable crossing overs between content and hardware. Through these developments, the separation of strict media regulation and telecommunications regulation has become obsolete and the functioning of the various regulators across these domains has become highly interdependent. The regulation of access to electronic communications networks by the OPTA affects to a considerable degree the regulation of market entrance of content providers (regulated by the Media Authority) and the allocation of frequencies (by the Radiocommunications Agency). The authors of the CPB report also urge to take careful not of the experiences in the United Kingdom, the United States and Australia. The UK has created in 2002 the sector-specific regulator Office of Communications (Ofcom), which is the outcome of a merger of the Broadcasting Standards Commission, the Independent Television Commission, the Office of Telecommunications, the Radio Authority, and the Radiocommunications Agency. The Federal Communications Commission in the US has been responsible for the regulation of telecommunications, spectrum and broadcasting for a very long period. And the same is more or less the case for the Australian Communications and Media Authority. The CPB report hence suggests considering the merger of the OPTA (without the postal division), the Media Authority and the Radiocommunications Agency in this light.

Besides convergence, the CPB also mentions two other factors that argue in favor of strictly maintaining a divide between ex ante and ex post regulation. First, ex ante regulation of network access was still much needed, as the telecommunications sector is not competitive yet. Even though broadband internet networks have made substantial headways as deliverers of internet, media and telephone service, their existence has according to this report not led to the abolishment of access regulation (De Bijl 2011, p. 5). It is also reported that competition between wireless phone networks and fixed lines is weak, as the former cannot yet match the speed and quality of the latter (De Bijl 2011, p. 6). The second argument in favor of keeping ex ante and ex post separate is the fact that modern economy and society have become highly dependent upon electronic communications. Internet has evolved into a domain for forms of social interactions, innovation and entrepreneurship. ICT has also become vital for designing new industrial processes and logistics and plays an important role in countries' national security policies. At the same time, Internet has created dangers; privacy protection, cyber crime, identity theft are examples. These developments, according to the report, require ICT regulators. 
Another authoritative source that has assessed the degree of convergence is a report that the RAND Corporation prepared in 2008 in commission of OPTA (Van Oranje-Nassau et al, 2008). RAND has examined the magnitude of convergence of the communications and audiovisual markets and its likely impact on regulations and market governance. RAND concludes that through a number of technological advances the traditionally separated spheres of broadcasting and telecommunications has been rapidly fading away. The report concludes that the two sectors, which were driven by distinct values and concerns, have been growing towards each other. Whereas broadcasting has been dominated by public interest concerns of free speech, ethical and social norms regulation (e.g. decency, protection of minors), telecommunications was preoccupied by economic and technical issues centering on access and affordable costs of service delivery by the government-owned incumbent telecoms operator. Convergence has resulted in a mix-up of these sectors leading to a blending of content, bundling and creation of (new) network infrastructure, and public interests. The report cautions policymakers to respond in a one-size-fitsall manner, however. Technological innovations are an ongoing process and the future directions of the process convergence will take cannot easily be predicted. Convergence needs a regulatory response, to be sure, but that response should take into account a variety of instruments, such as self- and co-regulation, stakeholder and expert consultations, ex ante instruments (e.g. spectrum allocation), and general competition policies. In other words, the RAND reports is less adamant than the CPB in calling for ICT regulator, but the report confirms the ongoing evolution of convergence within the communications sector.

\section{The decision not to merge OPTA with the Media Authority and Radio-communications Agency}

Based on the report of RAND and the government's previous policy briefs, the junior minister of Economic Affairs wrote in a letter to the Second Chamber that the government considered three alternative models for regulatory design of the telecommunications sector (Kamerstukken II, 20102011, 31 490, nr. 55):

1. Regulatory cooperation between OPTA, Radiocommunications Agency, Media Authority, Competition Authority and Consumers Authority

2. The 'chamber model': OPTA becomes a division (i.e. a 'chamber') within the Competition Authority

3. A sectoral regulator: OPTA merges with Radiocommunications Agency, and the Media Authority

The first alternative is based on the expectation that convergence can take on different shapes and continue in directions that cannot be foreseen. In such a scenario, the government opts for the status quo where OPTA and other regulators are functioning as independent entities. Cooperation between the regulators is secured through various cooperation protocols

('samenwerkingsprotocols'), i.e. the formal regulatory coordination model, that are drafted among regulators to coordinate their activities in cases where their competences and jurisdictions overlap or when certain cases require joint action. Alternative two was considered adequate only if the degree of competition, which is the case when convergence is progressive, reaches a mature level such that close coordination between ex ante and ex post regulation becomes a prerequisite for regulating the media and communications sectors. In this scenario, the need for sector specific regulation declines but is still deemed necessary. As long as sector specific regulatory tasks are closely intertwined with tasks related to protecting the general interest, the chamber model is considered less preferable. The chamber model would fit an environment where convergence makes it difficult to demarcate clearly the boundaries of various markets. To establish organic linkages between ex ante and ex post it s necessary to forge cooperation protocols and agreements

The final alternative was the merger of the communications and media authorities - OPTA, Media Authority and Radiocommunications Authority - and the establishment of an ICT regulator. The benefits of such a regulator is that it would oversee the entire converging sectors and therefore find 
itself in a better position to protect public interests, such as protecting the diversity of supply of content within highly competitive markets. However, according to the Minister, a problem with this alternative is that the regulators are substantially different from each other in terms of their tasks, working procedures, and legal frameworks (i.e. Telecoms Act and the Media Act). The Radiocommunications Agency manages the Dutch frequency spectrum, the OPTA ex ante regulates sector specific competition issues and the Media Authority ex post monitors broadcasting programs, often specifically from the perspective of the freedom of speech and expression. At the time of the writing of this letter, these tasks were considered to be too divergent for merging the three authorities, but the letter explicitly states that ongoing convergence in these domains will not preclude the redesign of regulation along the lines of this alternative (Ministry of Economic Affairs, Agriculture and Innovation 2011, p. 13). Two years later, the government finally decided that alternative three above was unfeasible and undesirable. The option to merge OPTA with the Media Authority and the Radiocommunications Agency was then finally dismissed.

In conclusion, although two reports from authoritative institutions independently argue that convergence is a complex but still undeniable force that both shapes the contours of telecommunications sector and calls policymakers to adequately adapt their regulatory instruments to this development, the Dutch government has not chosen for the creation of an ICT regulator. The Dutch government does refer to the conclusion of RAND and the Ministry of Economic Affairs, Agriculture and Innovation acknowledges the importance of the convergence of media and electronic communications,. The Ministry also underscores one of the conclusions of the RAND that states that the future direction of convergence remains uncertain (Kamerstukken II, 20052006, 24 095, nr. 195, Kamerstukken II, 2005-2006,26 643, nr. 81, Kamerstukken II, 20062007,24 095, nr. 209). This line of reasoning can be found in the Letter of the Junior Minister of Economic Affairs to the Second Chamber of 21 December 2009 (Kamerstukken II, 2009-2010, 32 123 XII, nr. 47) and the policy brief on convergence (Kamerstukken II, 2007-2008, 26643 \& 24 095, nr. 126). Therein the government pointed at one of RAND's future scenarios that convergence could lead to fully working competitive market (in case infrastructures and services are not integrated and there is competition between different infrastructures). In other words, to back the rejection of an ICT regulator the government seems to have made use of the open-ended scenario's provided by the RAND report.

\section{Motivations for the merger of OPTA with the general competition authority}

In his letter of 28 March 2011, the Minister of Economic Affairs, Agriculture and Innovation kicks off the process of the merger of OPTA, NMa and the Consumer Authority (Kamerstukken II, 20102011,31490 , nr. 55). The key word is "synergy" and the efficiency gains that can be hold of when these three regulators are merged, because market regulation can be made more flexible and integral. What is more, the new authority will incorporate next to competition regulation and sectorspecific regulation also responsibilities for consumer protection. In the letter of the minister this is phrased as follows:

"All [regulators] are charged with market regulation on partially the same (partial) markets; they all make market analyses within their own task domains and have a legal service or discipline (sic). Increasing internationalization and (technological) developments deem the sharing of this knowledge and regulatory strategy more important. Similarly, some markets in transition (for example, post and telecommunications) develop more towards competitive markets as a result of which market regulation can take place more often in an ex post mode. This does not alter the fact that because of the specific network characteristics an certain amount of sector specific regulation is necessary to safeguard competition in network sectors" (Kamerstukken II, 2010-2011, 31 490, nr. 55, p. 4)

A merger is seen as a more effective mechanism than cooperation protocols for the organization of sector-specific regulation and the bundling of ex ante and ex post regulation on these markets. The 
Dutch Competition Authority, that already has sector-specific regulation incorporated within the organization, demonstrates, according to the government, how synergy can be gained concerning ex ante and ex post regulation. Synergies can, more precisely, be gained by reducing the number of board members, staff, and streamlining of the administrative and financial management of the new body. Cooperation protocols are no longer needed and the (internalized) coordination costs for both the government as well as authority is reduced.

\section{Conclusion}

Within the telecommunications and media sector, technological innovations occur at a rapid pace. The traditional boundaries between telecommunications, broadcasting and content are blurring. Advances in the field of infrastructure technologies create new business models and the development of new products. These changes have repercussions for the organization of markets and the regulation of those markets as the fusion of technologies hampers effective regulation. Where communication and media technologies cross over it becomes more difficult to adequately demarcate markets. At the same time, technological innovation spurs competitiveness and policymakers are confronted with pressures to elevate ex ante regulatory regimes and to replace them by standard competition regulation. Finally, the blending of technologies with content produces new sorts of breaches of fundamental rights and forces policymakers to think anew (the limits of) consumer protection.

These developments raise important challenges for policymakers with regard to the institutional design of regulatory regimes. This chapter has examined the case of the institutional redesign of telecoms regulation in the Netherlands. The case has actually been about the Dutch policymakers' response to the triple challenge of convergence, competition and public interest regulation in the telecoms sector. In this chapter we saw that Dutch policymakers have opted for the ending of sector-specific telecoms regulation and to redesign the system of telecoms regulation along the lines of general competition regulation. By doing this, they consciously ruled out the maintenance of single sector regulation as well as the establishment of an ICT regulator. Both options were viable as the debate about the status (or lack) of technological convergence and the degree of competitiveness within the telecoms sector remains a highly debated issue among policymakers and experts. This chapter tried to shed light on the motives behind the decision of merger by analyzing the decision-making process from two theoretical perspectives. These two perspectives, i.e. contingency theory and structural choice theory, provide us with two alternative motives of decision-making. According to the former theory, policymakers would have based their decision upon the attributes of the environment of telecoms regulation. They would have let contingencies inform their perspectives about the institutional design of the telecoms regulator. In this case this would have meant that the institutional design of telecoms regulation would have been the function of policymakers' belief about the degree of convergence in the telecoms sector. Would the structural choice perspective have prevailed, then, the institutional design of telecoms regulation would have been the function of policymakers' beliefs concerning the costs of coordinating the regulatory regime and the costs that would be imposed upon market parties.

In this chapter we found that Dutch policymakers were informed about the state of the technological convergence. We saw that their views about convergence were partly informed by external expert reports. In the end, they took these views into consideration but did not attach sufficient weight upon them to opt for an ICT regulator, i.e. a merger between OPTA and the Media Authority. More specifically, among Dutch policymakers took hold the view that the process of convergence is too unpredictable for creating an ICT regulator. In the current situation, they seem to have opted for reducing coordination costs, i.e. creating "synergies", by merging OPTA with $\mathrm{NMa}$ and the Consumer Authority. These observations imply that political considerations prevailed in the end. Policymakers withstood the pressures to opt for contingency-informed designs and chose for the regulatory model with the least amount of coordination costs for the government. By integrating the telecoms regulator within the general competition authority, policymakers 
'decentralized' their coordination costs to the regulator. Does this mean that the theory of the politics of structural choice unambiguously prevails? On the basis of this single case, we are inclined to say "yes". Illustrative evidence for this way of inferring from the data is the policymakers' downplaying (in the case of the RAND report) and neglect (in the case of the CPB report) of positive evidence for the convergence thesis found in the expert reports, on the one hand, and the emphasizing of the "synergy" and economies of scale arguments that are so stressed within the government briefs in which the case is made for the merger. Despite the fact that political power to decide for any design alternative lies in the hands of policymakers, and hence any instance of institutional design can in principle be argued in favor of the structural choice thesis, we also see a strong role of arguments: the Dutch policymakers needed proper and substantive counterarguments to argue in favor of the merger alternative instead of the ICT sectoral regulator alternative.

Of course, an important caveat is at work here.. The case presented in this chapter remains limited to a single decision in one country. However, the question this case evokes are important for many other instances of regulatory design. The broader and generic question is whether policymakers who are confronted with complex and ambiguous - "wicked" - policy puzzles are capable of responding in an adequate way. A main issue is the question how and to what extent institutional design can address the dynamics and ambiguity of regulatory challenges.

\section{References}

Aldrich, Howard E. (2008). Organizations and Environments. Stanford, Cal.: Stanford University Press.

Amburgey, Terry L. \& Rao, Hayagreeva (1996), 'Organizational Ecology: Past, Present, and Future Directions', Academy of Management Journal, 39(5), pp. 1265-1286.

De Bijl, Paul W.J. (2011) Verstrengeling van media en telecommunicatie. Regulering blijft nodig. CPB Policy Brief 2011/02. Den Haag: CPB.

Donaldson, Lex (2001) The Contingency Theory of Organizations. Thousand Oaks, Cal. Sage Publications.

Epstein, David, and Sharyn O'Halloran. 1999. Delegating powers: A transaction cost politics approach to policy making under separate powers. New York: Cambridge University Press. Garcia-Murillo, Martha \& MacInnes, Ian (2003) 'The Impact of Technological Convergence on the Regulation of ICT Industries' International Journal On Media Management, 5(1), pp. 57-67 Gilardi, Fabrizio. 2002. Policy credibility and delegation to independent regulatory agencies: A comparative empirical analysis. Journal of European Public Policy, 9:873-93.

Hammond, Thomas $x$ (1996) 'Who controls the bureaucracy?: Presidential power, congressional dominance, legal constraints, and bureaucratic autonomy in a model of multi-institutional policymaking', Journal of Law, Economics, and Organization, 12 (1), pp. 119-166 Hannan, Michael T. \& Freeman, John (1989). Organizational Ecology. Cambridge, Mass.: Harvard University Press.

Henten, Anders, Samarajiva, Rohan \& Melody, William (2003), ' Designing Next Generation Telecoms Regulation: ICT Convergence or Multi-Sector Utility?', Info, 5(1), pp. 26-33. Herring, Richard and Jacopo Carmassi (2008), "The Structure of Cross-Sector Financial Supervision", Financial Markets, Institutions and Instruments, 17(1), pp. 51-76.

Horn, Murray J. (1995) The political economy of public administration: Institutional choice in the public sector. New York: Cambridge University Press.

Huber, John D., and Charles R. Shipan. (2002). Deliberate discretion?: The institutional foundations of bureaucratic autonomy. Cambridge, UK: Cambridge University Press. Jordana, Jacint \& Levi-Faur, David (2010), 'Exploring Trends in Agency Scope', Jerusalem Papers in Regulation and Governance, Working paper no. 27 (http://regulation.huji.ac.il/papers/jp27.pdf) 
Levi-Faur, David (1999), 'Governing Dutch telecommunications reform: state-business interactions in the transformation of national policy regimes to (European) embedded policy regimes', Journal of European Public Policy, 6(1), pp. 102-122

Lewis, David E. (2003) Presidents and the politics of agency design. Political institutions in the United States Government Bureaucracy, 1946-1997. Stanford, CA: Stanford University Press. Ministry of Economic Affairs, Agriculture and Innovation (2011) Kamerbrief samenvoeging NMa, OPTA en Consumentenautoriteit. Den Haag Moe, Terry (1995) 'The politics of structural choice: Toward a theory of public bureaucracy,' In Organization theory: From Chester Barnard to the present and beyond, ed. Oliver E. Williamson, 116-53. New York: Oxford University Press

Samarajiva, Rohan, Amy Mahan and Andrew Barendse (2002), Multisector Utility Regulation, Discussion Paper \# 0203, World Dialogue on Regulation for Network Economies (WDR)

Second Chamber, Kamerstukken II 1996-1997, 25128, nr. 3.

Second Chamber, Kamerstukken II, 2005-2006, 24 095, nr. 195.

Second Chamber, Kamerstukken II, 2005-2006, 26 643, nr. 81.

Second Chamber, Kamerstukken II, 2006-2007, 24 095, nr. 209.

Second Chamber, Kamerstukken II, 2007-2008, 26643 \& 24 095, nr. 126

Second Chamber, Kamerstukken II, 2009-2010, 32123 XII, nr. 47.

Second Chamber, Kamerstukken II, 2010-2011, 31 490, nr. 55.

Schwartz, Tim and David Satola (2000), Telecommunications Legislation in Transitional and Developing Economies, World Bank Technical Paper No. 489. Washington DC: World Bank Group.

Tsebelis, George (2002) Veto Players. How Political Institutions Work. Princeton, NJ: Princeton University Press

Van Oranje-Nassau, Constantijn, Cave, Jonathan, Van der Mandele, Martin, Schindler, Rebecca, Yeong Hong, Seo, Iliev, Ilian \& Vogelsang, Ingo (2008). Responding to Convergence. Different Approaches for Telecommunications Regulators. Rand Corporation, Prepared for OPTA. Cambridge, UK: Rand Corporation.

Verhoest, Koen, Matthijs, Joery, Aubin, David \& Mathieu, Emmanuelle (2010), 'Multilevel regulering van nutssectoren: Telecommunicatie en energie in België', Vlaams Tijdschrift voor Overheidsmanagement, 4(16), pp. 43-50

Yesilkagit, Kutsal (2004), 'Bureaucratic Autonomy, Organizational Culture, and Habituation Politicians and Independent Administrative Bodies in the Netherlands', Administration \& Society, 36(5), pp. 528-555

Yesilkagit, Kutsal \& Christensen, Jørgen G. (2010), 'Institutional Design and Formal Autonomy: Political versus Historical and Cultural Explanations', Journal of Public Administration Research \& Theory, 20(1), pp. 53-74. 